\title{
Proceeding
}

9th INSHS International Christmas Sport Scientific Conference, 4-6 December 2014. International Network of Sport and Health

Science. Szombathely, Hungary

\section{A field research: evaluation of efficiency of P.E. lessons}

\author{
BRIGITA STLOUKALOVÁ $\square$, TOMÁŠ ROZTOČIL, DANA FIALOVÁ, ZDENĚK CHLUP \\ Department of P.E. and Sport, Faculty of Education, University of Hradec Králové
}

\begin{abstract}
Stloukalová, B., Roztočil, T., Fialová, D., \& Chlup, Z. (2015). A field research: evaluation of efficiency of P.E. lessons. J. Hum. Sport Exerc., 9(Proc1), pp.S526-S536. Introduction: We focused on the efficiency evaluation of some forms of exercise used often for the loading and growth of physical load in the P.E. lessons. The aim of our research was to create and realise exemplary P.E. lessons oriented to fitness development and to measure data (lesson timing, heart rating). The short relays and indoor parcourse were selected forms of exercise. The observing was an initial method. We measured physiological time (tf), pedagogical time (tp) and fault time (tz). The physical load was assessed through a heart rate. Two pupils in every PE lessons were measured. During evaluation of the PE lesson efficiency we watched a) total physiological time in the lessons; b) total time of loading in the middle and higher intensity zone. The measured heart rating characterising middle and higher intensity zones and the total time of the activity in these zones showed both of used forms filled demands on the PE lessons; the parcourse are physiologically more effective than the short relays. Keywords: HEALTH-ORIENTED EFFICIENCY, HEALTH-ORIENTED PE, PHYSICAL LOAD, FITNESS, INDOOR PARCOURSE, SHORT RELAYS.
\end{abstract}

Corresponding author. Brigita Stloukalová, KTVS, PdF, University of Hradec Králové, Rokitanská 62, 50003 Hradec Králové, Czech rep.

E-mail: brigita.stloukalova@uhk.cz

9th INSHS International Christmas Sport Scientific Conference, 4-6 December 2014. International Network of Sport and

Health Science. Szombathely, Hungary.

JOURNAL OF HUMAN SPORT \& EXERCISE ISSN 1988-5202

(c) Faculty of Education. University of Alicante

doi:10.14198/jhse.2015.10.Proc1.48 


\section{INTRODUCTION}

A sedentary lifestyle and poor diet are the main reasons for low levels of today's children's fitness and also for a large percentage of obesity. The latest research in this area shows that overweight children living a sedentary lifestyle have a much higher chance of developing degenerative diseases, and in addition these diseases occur at an earlier age (Snethen \& Broome, 2007; Galloway, 2007). Within the framework of population surveys in the Czech Republic, it was found that approximately $55 \%$ of school-age children attend school Physical Education (P.E.) only, with no further physical activity. Less than $50 \%$ of school-age children regularly go in for organized sports activities. Their number is significantly greater in middle childhood, while in adolescence or preadolescence their number decrease (Jansa \& Kocourek, 2001; Suchomel, 2002).

Physical education in schools must adapt to this situation and focus on encouragement of all pupils with special attention to those who are less physically active or even inactive (Zhang \& Chen, 2014; PHIT America, 2014). P.E. classes focus on motor skills, development of motor skills and physical fitness and educational impact on students towards a healthy lifestyle (Framework Educational Programme, 2013). In 45 minutes twice a week, this task is essentially impossible. What can the P.E. teacher do?

In our thesis, we have focused on evaluating the effectiveness of certain forms of exercise commonly used for loading and increasing of physical exercise in P.E. classes. For the purposes of our study, by forms of exercise we mean the didactic arrangement of space and the character of interaction between a teacher and students.

Our aim was to measure the values of selected indicators and compare them with usual standards (Polar.com, 2015; Soumar, 1997). In light of these indicators, we evaluated the efficacy of the model P.E. lessons.

\section{MATERIAL AND METHODS}

\section{Participants}

The measurement was always done on two test participants simultaneously (hereafter TP). It was an intentional choice; the first TP had been regularly active in sports at the competition level; the second TP had not been doing any sport activities, regularly or otherwise (Table 1).

\begin{tabular}{ccccc}
\multicolumn{5}{c}{ Table 1. Characteristics of Test Participants } \\
\hline TP & sex & age & sport activity & form of exercise \\
\hline 1 & boy & 15 & yes & short relays, indoor \\
2 & boy & 15 & no & parcourse \\
5 & girl & 14 & yes & short relays \\
6 & girl & 14 & no & \\
7 & girl & 14 & yes & indoor parcourse \\
8 & girl & 14 & no & \\
\hline
\end{tabular}




\section{Measures}

First, we measured the heart rate using a training computer. To determine the range of individual intensities we chose a theoretical calculation of maximum heart rate according to the formula $H R_{\max }=220$ - age, and coefficients to determine the zones of individual intensities. For our purposes, we were interested in two zones, the zone from 60 to 70 percent, and the zone from 70 to 80 percent of $\mathrm{HR}_{\max }$ (Figure 1).

\begin{tabular}{|ll|l|l|l|}
\hline zone & \multicolumn{1}{c}{ coefficient $(\%$ of HRmax) } & \multicolumn{1}{c|}{ activity duration } & HR range & intensity \\
\hline very light & $\mathbf{5 0 - 6 0}$ & more than $60 \mathrm{~min}$ & $102-123$ & low \\
\hline light & $60-70$ & $30-60 \mathrm{~min}$ & $124-143$ & midd le \\
\hline moder ate & $70-80$ & $10-30 \mathrm{~min}$ & $144-164$ & higher 1 \\
\hline hard & $80-90$ & $\mathbf{5}-10 \mathrm{~min}$ & $165-184$ & higher 2 \\
\hline maximum & $90-100$ & $1-5 \mathrm{~min}$ & $185-205$ & maximal \\
\hline
\end{tabular}

Figure 1. Characteristics of loading zones (processed by Soumar, 1997)

Next, we performed our observations with timekeeping. We measured physiologically utilized time ( $\mathrm{t}_{\mathrm{f}}$ ), i.e. the time when the development of motor skills and physical load can be reached.; teaching time ( $\left.t_{p}\right)$, i.e. the time during which the teacher organizes and explains tasks and instructs the pupils, plus the time allocated to the pupils' cooperation during the preparation of the gym; and idle time ( $\left.\mathrm{t}_{\mathrm{z}}\right)$, in which the pupils are passive. We recorded the lessons to (among other things) receive feedback and keep control of the measured data.

Due to the low number of TP (it is not possible to test more people by the training computer during one P.E. lesson) we do not proceed with a statistical evaluation of the measurement. The research is considered to be a pilot study in which we verified the procedure for obtaining data in the field.

\section{Procedures}

We prepared a plan for model P.E. classes with a focus on fitness exercises. These P.E. lessons were implemented with ninth-grade pupils at two elementary schools in Hradec Králové. In this article we present the results that were achieved in short relay races and on small indoor parcourse.

All model lessons were first tried out in the classroom with our students to verify the lessons, to test the timekeeping and to coordinate the four-member implementation team. After that we had "testing lessons" with pupils to introduce them to the content and organization of the lessons and then we proceeded to the actual measurements. For the research, we chose simple field methods, which can also be applied in everyday teaching practice.

The short relay races characteristic

Short relay races use running drills, "short overshoots" with simple tasks, throw and run actions and short lap runs. We used non-competitive performance with an emphasis on movement technique, and also competitive performance. The short relay races were performed on 5- to 10-meter segments in 4 groups of 4-5 pupils. Pupils achieved high movement intensity, and the ratio of physical activity to the rest interval was 1:5. 
The small indoor parcourse characteristic

For indoor parcourse the main principle is to overcome various obstacles, which encourages the development of individual components of agility skills. Our indoor parcourse was built on the entire area of the gym in four rows of 18 meters with a total length of 90 meters. We included jumping over or crawling under the obstacles, running over benches, running around obstacles, a change of direction in space, and rolls. Each pupil ran three times at low intensity (1:10 min) and three times at high intensity (0:55 min) with a 3:00 min rest interval.

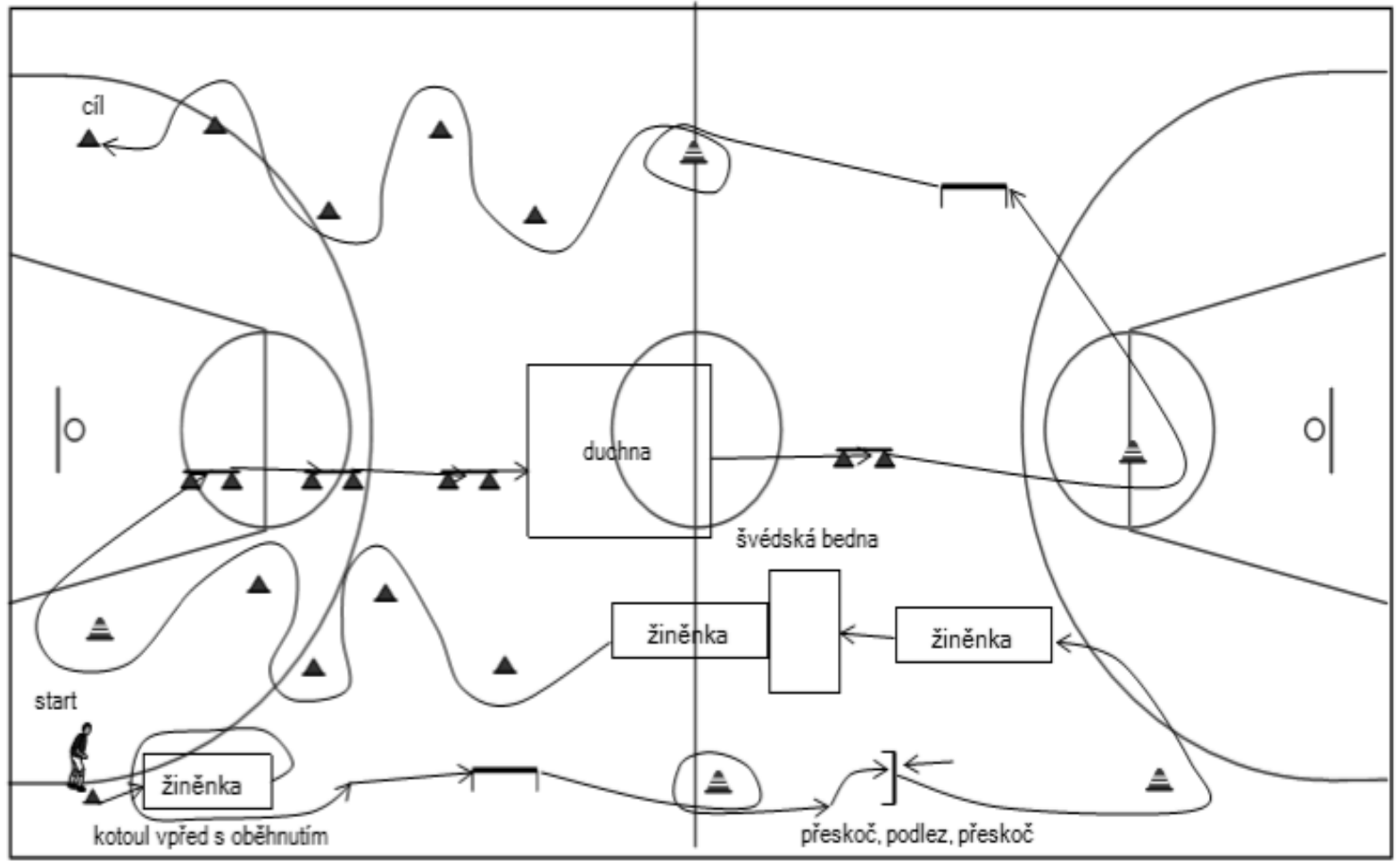

Figure 2. Diagram of the small indoor parcourse

\section{RESULTS}

In Figure $3 a$ and $3 b$, we can see the heart rate records of boys, and in Figure $3 c$ and $3 d$ of girls, that were reached in the short relay race lesson. We can see the climaxes in the busy part of the lesson, and then 17 peaks in the main part of the lesson. These peaks correspond with the activity of each TP during the relay races. Figure $3 \mathrm{~b}$ and $3 \mathrm{~d}$ show that rates of TPs who were not regularly engaged in sports activities move within the higher zones of intensity and also that return to normal values is slower and more unstable. 


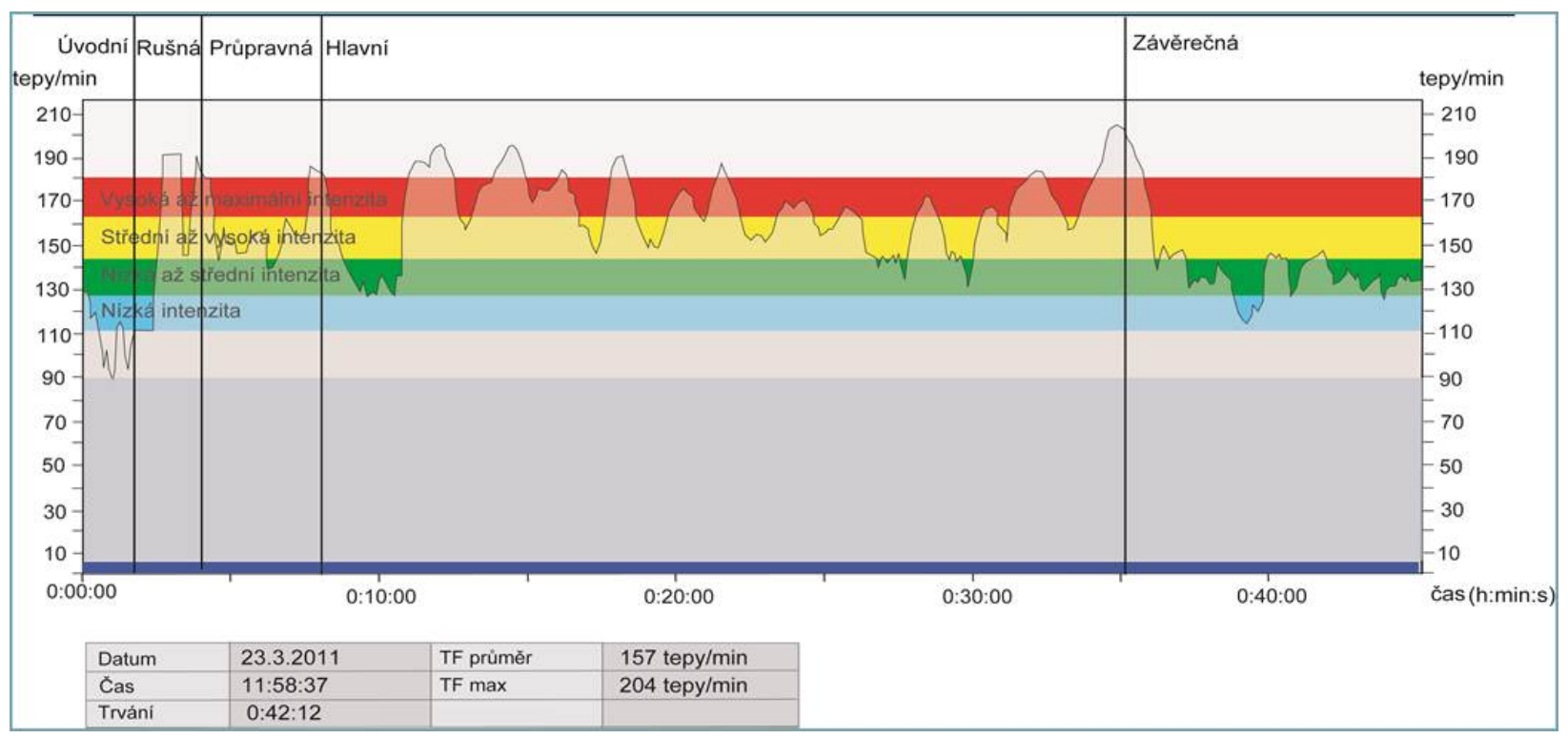

Figure 3a. Heart rate record of a boy - TP1 (relays)

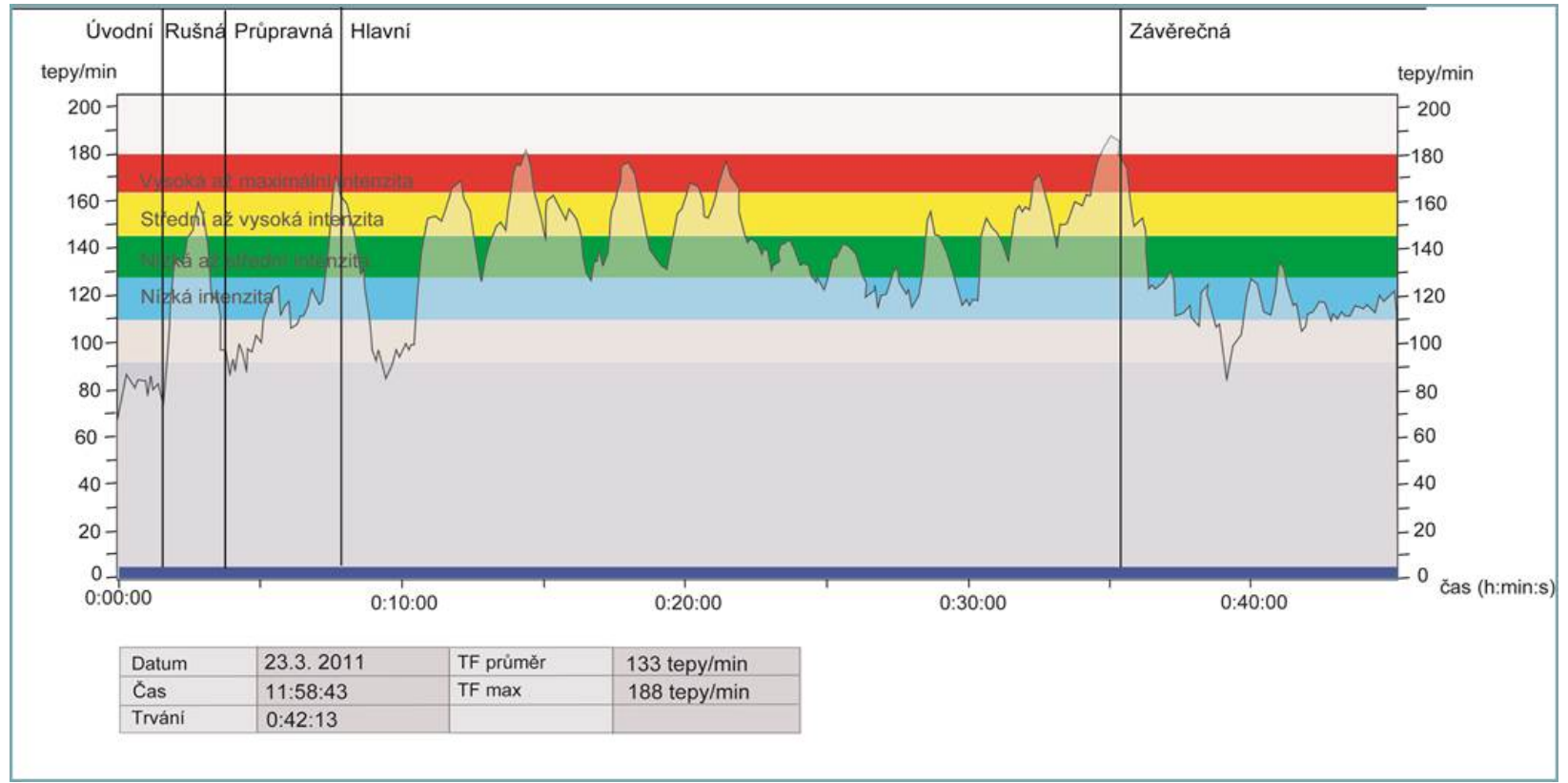

Figure $3 b$. Heart rate record of a boy - TP2 (relays) 


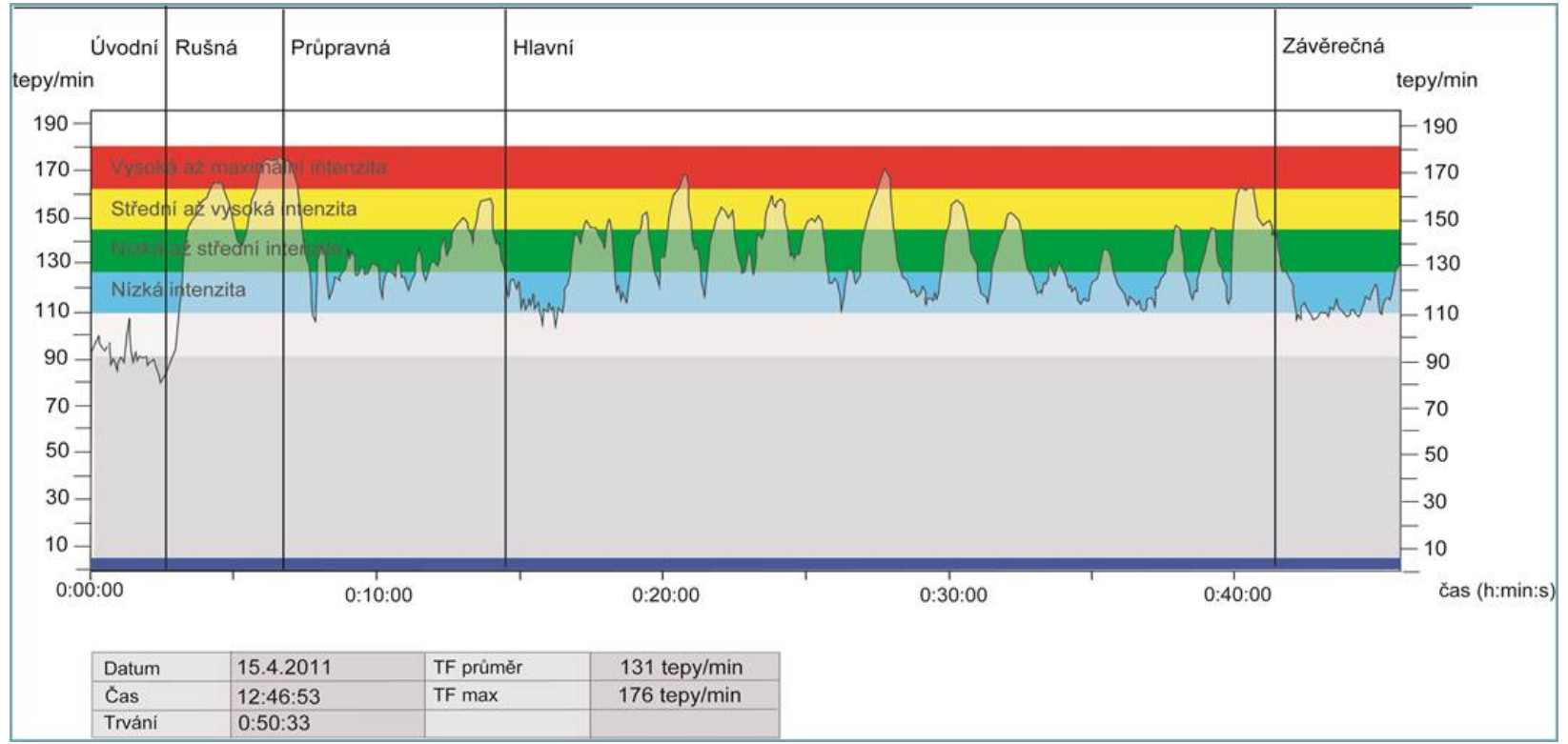

Figure 3c. Heart rate record of a girl - TP5 (relays)

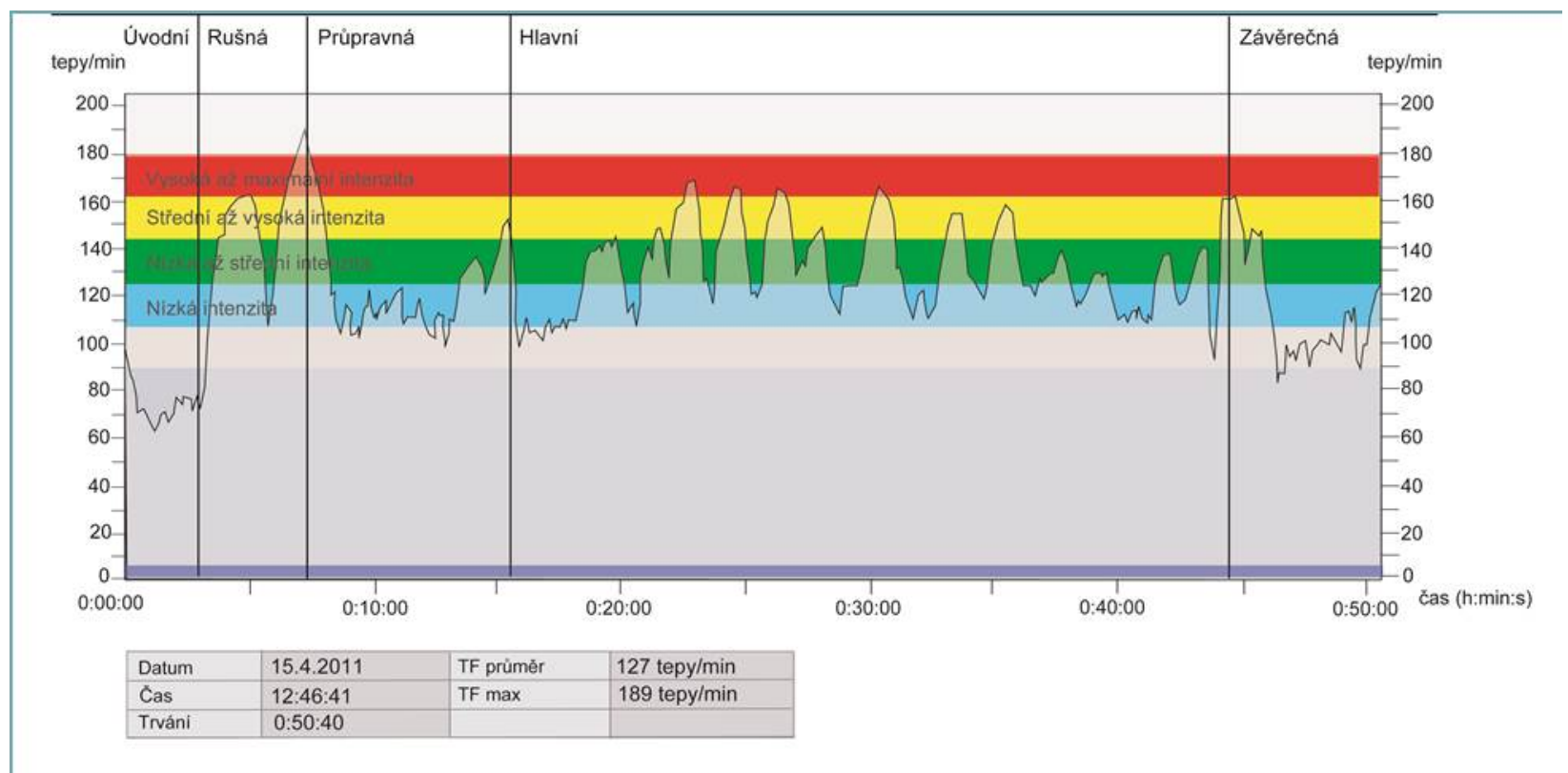

Figure $3 \mathrm{~d}$. Heart rate record of a girl - TP6 (relays)

In Figure $4 a$ and $4 b$, we can see the heart rate records of boys, and in Figure $4 c$ and $4 d$ those of girls, that were achieved in the small indoor parcourse lesson. The climaxes appear again in the busy and preparation parts of the lesson. There are 6 peaks in the main part of the lesson. Figure $4 \mathrm{~b}$ and $4 \mathrm{~d}$ show that pupils who were not involved in sports achieved higher average HR and higher maximum HR. 


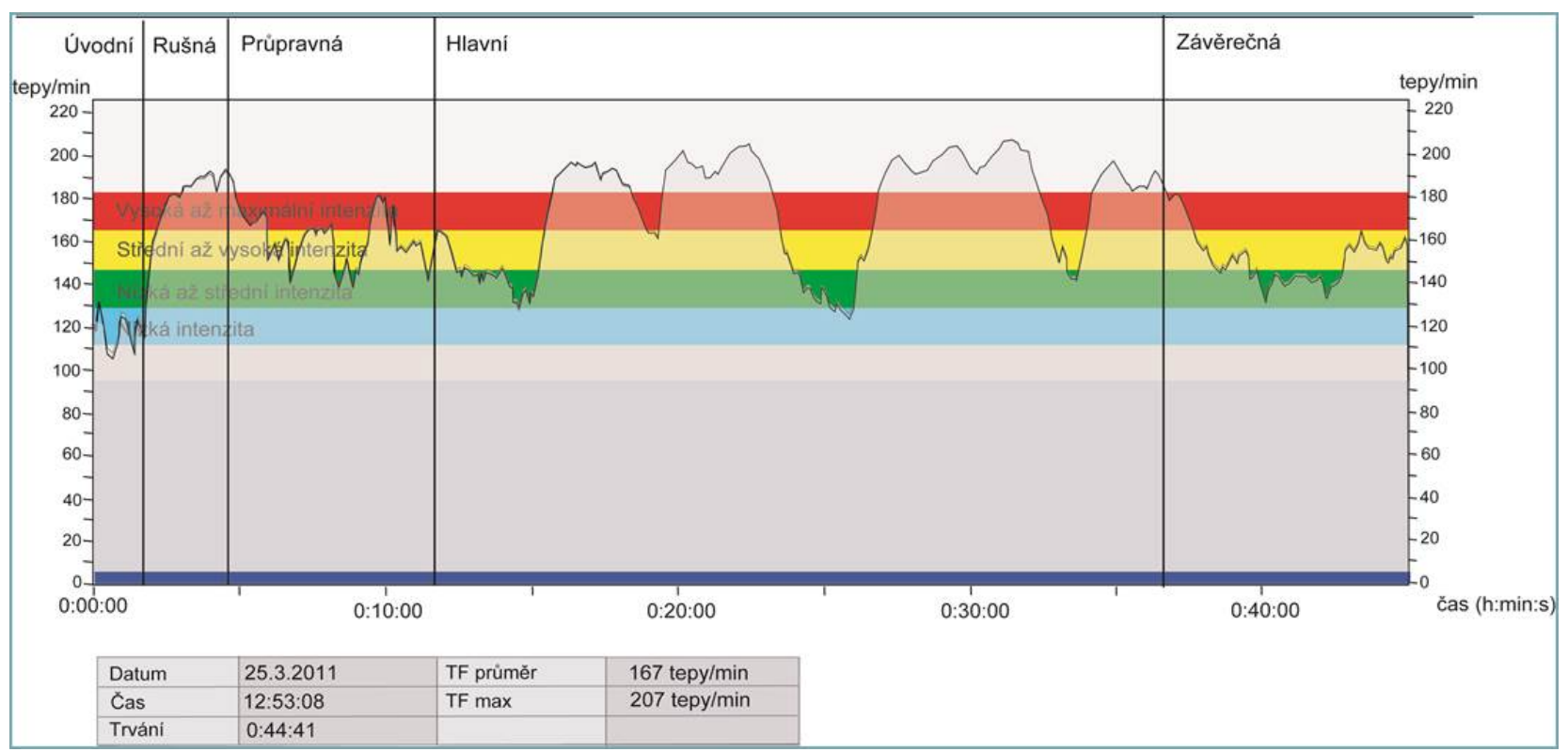

Figure 4a. Heart rate record of a boy - TP1 (parcourse)

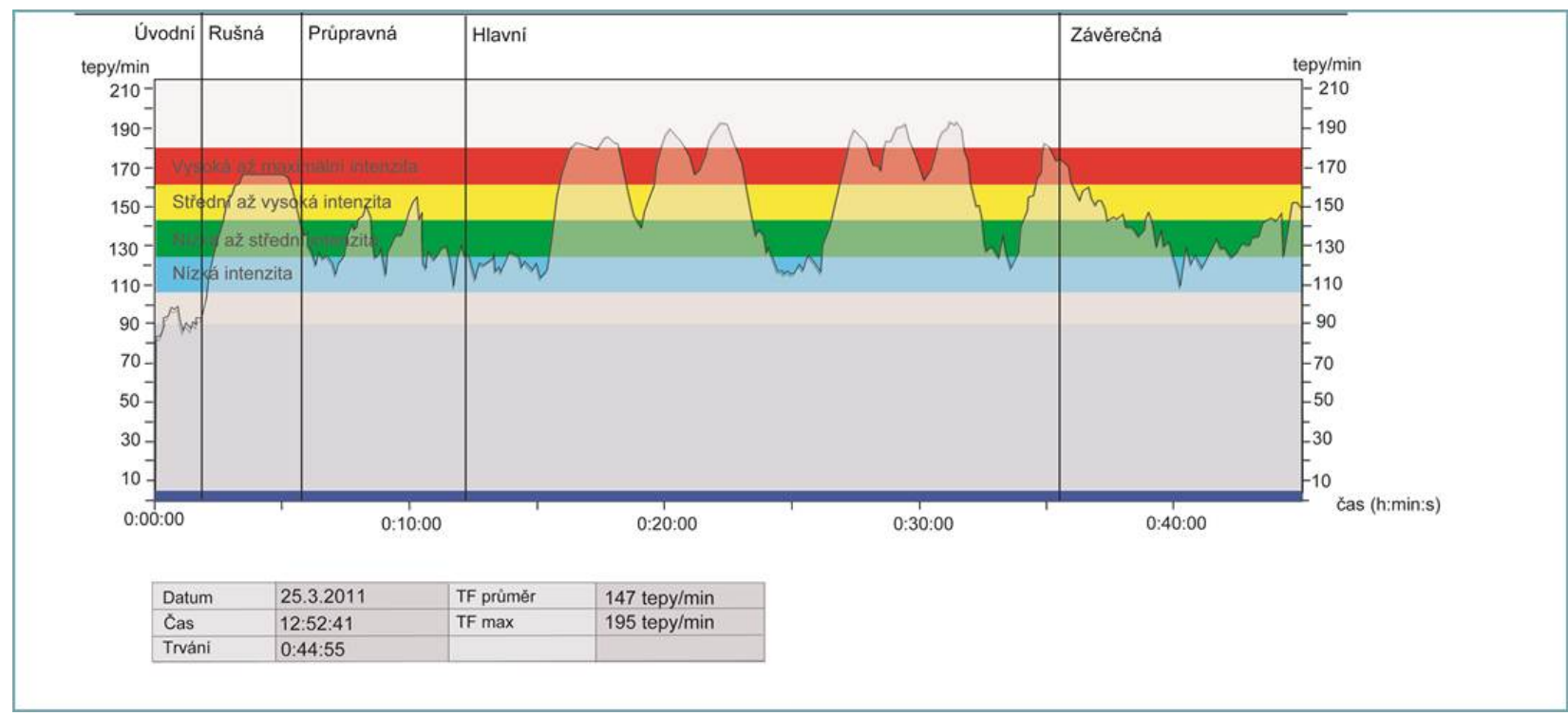

Figure 4b. Heart rate record of a boy - TP2 (parcourse) 


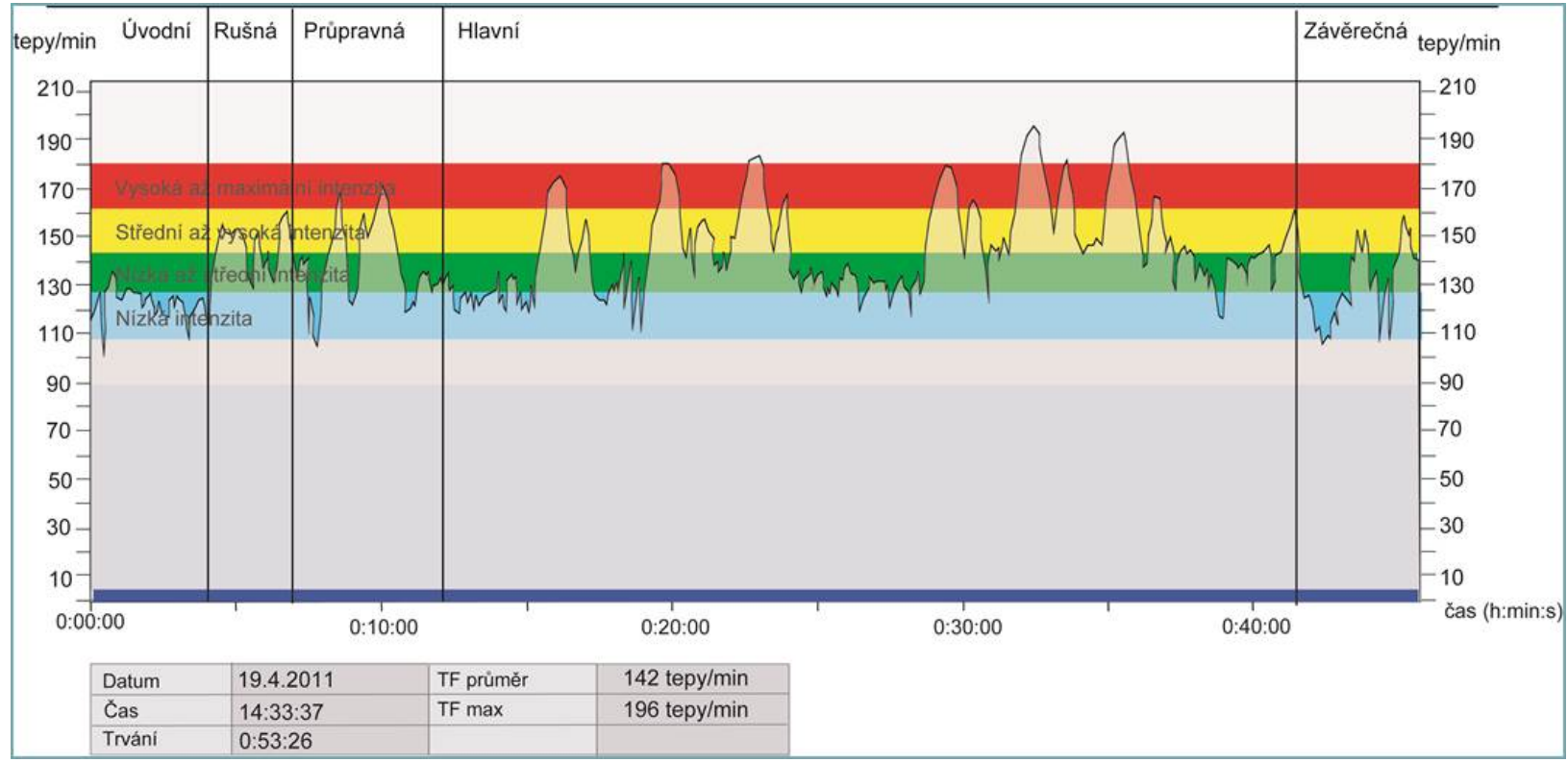

Figure 4c. Heart rate record of a girl - TP7 (parcourse)

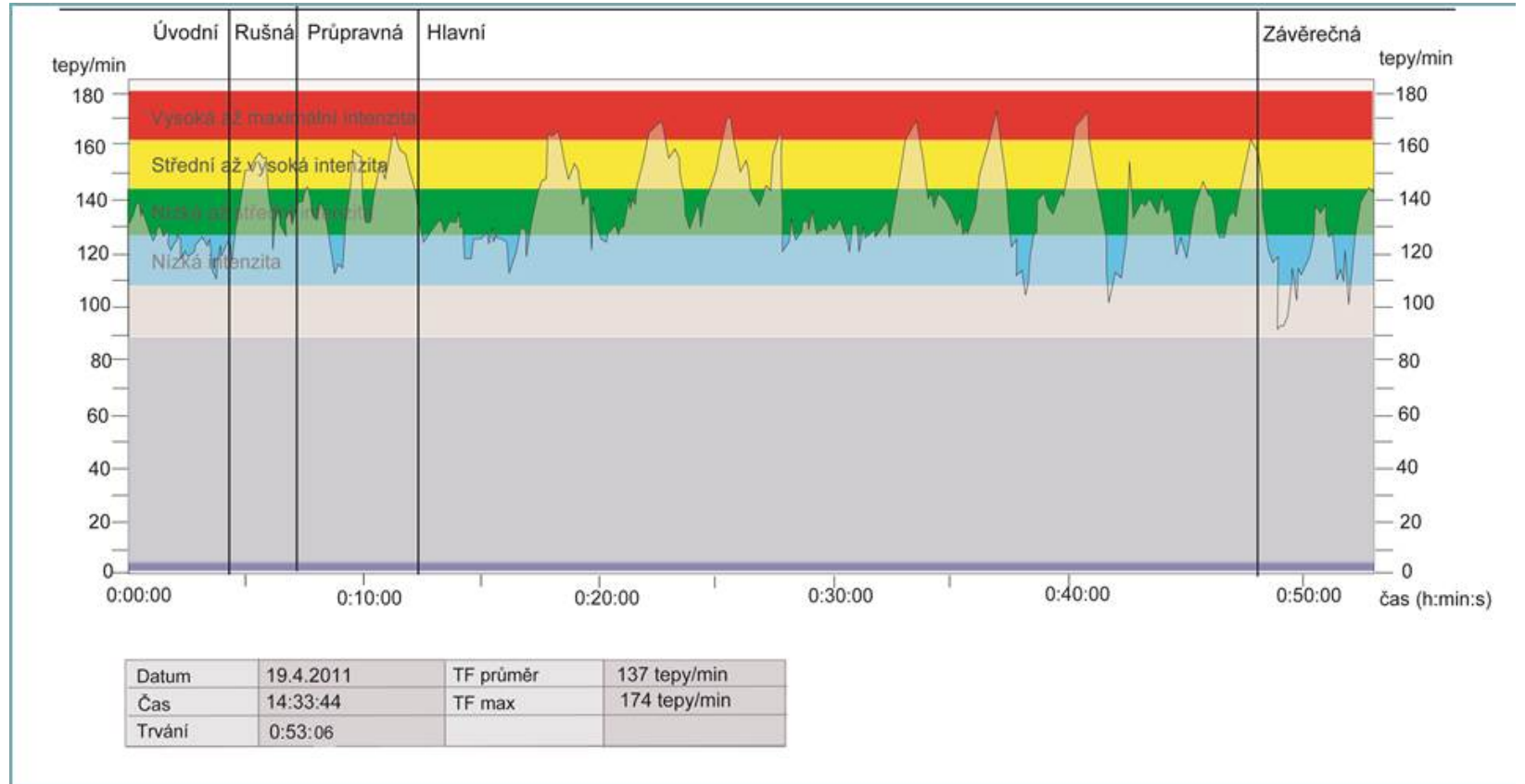

Figure 4d. Heart rate record of a girl - TP8 (parcourse)

\section{DISCUSSION}

In Table 2, there is an analysis, in minutes, of the recorded lessons. We continued to work with the data of the physiologically utilized time in the main part and its share of the physiologically utilized time in the whole teaching unit. By increasing the physical fitness, endurance and performance, we achieved permanent and 
general development of the physical abilities of pupils, depending on their sex and age. When evaluating the effectiveness of physical education lessons like this we were monitoring:

1. The total amount of physiologically utilized time in the lesson. An effective PE class is, according to Ciolac et al (2011) or Fjørtoft et al. (2010), a teaching unit, in which at least 20 minutes are used for physical activity, i.e., form a physiologically utilized time $t_{f}$.

2. The total loaded time in the stamina improvement and fitness improvement zones, i.e. the zones of 60 $80 \% \mathrm{HR}_{\max }$ (see $\mathrm{Tab} 3$ ).

Addendum 1. The requirement of 20 minutes for physical activity in the P.E. lesson is fulfilled in both types of lessons, the most in girls' parcourse. If you also look at teaching $\left(t_{p}\right)$ and idle $\left(t_{z}\right)$ time for boys, you can see that they show a slight tendency toward higher volume. Significantly higher idle time (over 12 minutes) was recorded for boys in the class focused on the indoor parcourse. By comparison with the other types of classes, the difference is so great that we consider it an extraordinary divergence caused by an unexpected situation in the class and we do not work with it hereafter.

The share of physiologically utilized time in the main part of the lesson is presented as a proportion of the total volume of this type of time in the last column of Table 2. We use this proportion to evaluate effectiveness of our methodology in the way we organized the forms of exercise we selected. This share is lower in short relay lessons. This type lays demands on the intensity of motion that require long periods of rest, which were also prolonged by a larger number of pupils in the groups. To compensate for this requirement, which is necessary in practice, we involve adequate load in the busy, preparatory and final sections. The small indoor parcourse lessons appear to be more effective in our case.

Table 2. Time of the lessons, in minutes and percentage of total time

\begin{tabular}{|c|c|c|c|c|c|c|c|c|}
\hline & \multicolumn{2}{|c|}{ tf VJ } & \multicolumn{2}{|c|}{ tp VJ } & \multicolumn{2}{|c|}{ tz VJ } & \multirow{2}{*}{$\begin{array}{c}\mathrm{tf} \mathrm{HČ} \\
\text { (mm:ss) }\end{array}$} & \multirow{2}{*}{$\begin{array}{c}t_{f} H C ̌ / t_{f} V_{J} \\
(\%)\end{array}$} \\
\hline & (mm:ss) & $(\%)$ & (mm:ss) & $(\%)$ & (mm:ss) & $(\%)$ & & \\
\hline $\begin{array}{c}\text { short relays } \\
\text { boys }\end{array}$ & 21:08 & 42.7 & 23:06 & 46.7 & $05: 17$ & 10.6 & $06: 20$ & 30,0 \\
\hline $\begin{array}{l}\text { short relays } \\
\text { girls }\end{array}$ & $19: 13$ & 47.8 & $15: 30$ & 38.6 & $05: 27$ & 13.6 & $05: 12$ & 27.1 \\
\hline $\begin{array}{l}\text { parcourse } \\
\text { boys }\end{array}$ & 20:03 & 42,0 & $14: 44$ & 30.9 & $12: 56$ & 27.1 & 08:34 & 42.7 \\
\hline $\begin{array}{l}\text { parcourse } \\
\text { girls }\end{array}$ & $26: 51$ & 63.3 & $09: 52$ & 23.3 & $05: 43$ & 13.4 & 09:09 & 34.1 \\
\hline
\end{tabular}

"Legend: tf - physiologically utilized time, tp - teaching time, tz - idle time, VJ - a teaching unit (model PE lesson), HČ - the main part of the lesson"

Addendum 2. This proportion also served as a criterion by which we could evaluate our initial choice of forms of exercise, and we found both forms met requirements. We used the range of zones for fitness development (light zone) and stamina improvement (moderate zone) when evaluating this indicator. The lower limit was set up to HR 120 per minute and the upper limit at HR 160 per minute. We evaluated the share of the time of the whole P.E. lesson when the pupil was in this range of the heart rate. The results are summarized in Table 3. 
In general we can say that the pupils were more often in the light intensity zone than in the moderate one and that we can observe the differences between pupils who engaged in sports (TPs 1, 5, and 7) and those who did not (TPs 2, 6, and 8). We want to focus on this fact in a separate thesis when we have more data from other measurements, but we can say pupils who do not engage in sports have higher average HR, higher $\mathrm{HR}_{\max }$, and spend more time in moderate and hard intensity zones. If we calculate the average values in Table 3 that were reached in individual lessons, we find that the indoor parcourse is the more effective form of exercise from the point of view of intensity of movement.

Some values of the data may seem low at the first sight, but further evaluation shows that quotients of the time in the zones of high intensity from 160 to 180 beats per minute are to considerable extended, especially in the case of the indoor parcourse. These data are influenced by the individual's level of aerobic fitness, increased level of motivation and also by a higher intensity of exercise, as well as other factors. In the short relay races lesson, the data placed the girl who did not engage in sports in the higher intensity zone $26,6 \%$ of the time.

Table 3. Time in intensity zones, in minutes and as a percentage expression (source: authors)

\begin{tabular}{|c|c|c|c|c|c|c|c|c|c|c|c|}
\hline & \multicolumn{11}{|c|}{$\mathrm{HR}$} \\
\hline & \multirow{2}{*}{ TP } & \multirow{2}{*}{$\begin{array}{c}\mathrm{HR} \\
\text { avarege }\end{array}$} & \multirow{2}{*}{ HRmax } & \multicolumn{2}{|c|}{ very light } & \multicolumn{2}{|c|}{ light } & \multicolumn{2}{|c|}{ moderate } & \multicolumn{2}{|c|}{ hard } \\
\hline & & & & $\mathrm{mm}: \mathrm{ss}$ & $\%$ & $\mathrm{~mm}: \mathrm{ss}$ & $\%$ & mm:ss & $\%$ & $\mathrm{~mm}: \mathrm{ss}$ & $\%$ \\
\hline short relays & 1 & 127 & 189 & $14: 30$ & 28.5 & $14: 40$ & 28.9 & $10: 30$ & 20.7 & $04: 45$ & 9.3 \\
\hline boys & 2 & 131 & 176 & $11: 30$ & 22.8 & $18: 25$ & 36.4 & $13: 15$ & 26.2 & 04:15 & 8.4 \\
\hline short relays & 5 & 133 & 188 & 09:20 & 22.1 & $10: 40$ & 25.2 & $10: 45$ & 25.4 & 06:00 & 14.2 \\
\hline girls & 6 & 157 & 204 & 02:00 & 4.7 & $07: 55$ & 18.7 & $12: 35$ & 29.8 & $11: 15$ & 26.6 \\
\hline parcour & 1 & 137 & 174 & $04: 35$ & 8.6 & $27: 50$ & 52.4 & $14: 45$ & 27.7 & $05: 30$ & 10.3 \\
\hline boys & 2 & 142 & 196 & $04: 20$ & 8.1 & $22: 50$ & 42.7 & $16: 30$ & 30.9 & $06: 35$ & 12.3 \\
\hline parcour & 7 & 147 & 195 & $04: 40$ & 10.4 & $14: 10$ & 31.5 & $08: 25$ & 18.7 & 08:10 & 18.1 \\
\hline girls & 8 & 167 & 207 & $01: 10$ & 2.6 & $04: 45$ & 10.6 & $13: 35$ & 30.3 & $07: 25$ & 16.6 \\
\hline
\end{tabular}

\section{CONCLUSIONS}

The main target of our work focuses on the didactics and methodology of P.E. lessons. We have created and put into practise model P.E. lessons using forms of exercise, short relay races and indoor parcourse, which are popular among P.E. teachers, while we evaluated the effectiveness of those forms.

There was a lower share of physically active time used in the main parts of the lessons presented in the measurement, which is due to increased demands on motion intensity with longer periods of rest in forms of exercise as they were organized and implemented according to our methodology.

With girls who did not pursue active sports, the heart rate exceeded 200 beats per minute for short periods of time.

The lessons, as they were implemented, meet the requirements of almost 20 minutes to be used for physical activity. In other words, they meet the requirements of physically utilized time $\left(\mathrm{T}_{\mathrm{f}}\right)$. Measured values of the heart rate, characterizing zones of intensities for the development of fitness and the improvement of stamina (range from 120-160 beats/min), and measured duration of physical activity in the zones, show that the chosen exercising forms meet the minimum regulatory requirements. 
What are the conclusions and recommendations of our research on teaching practice?

1. To expect lower physiological efficiency and compensate for it in the busy, preparatory and final part of the lesson while preparing lessons aimed at the development of speed (short relay races) or agility (parcourse).

2. To approach individually the pupils who do not do sport and movement activities outside school; for example, to adjust the number of repetitions and relaxation time among exercises.

3. To give enough attention and time to preparing P.E. lessons, and not to underestimate either this preparation or the subject itself. To take into account that the implementation of these forms of exercise and their effectiveness is preceded by long-term work with pupils, in which we consistently practise motor skills, introduce different types of exercises and its effects and benefits for pupils.

\section{REFERENCES}

1. Ciolac, E.G., Bocchi, E.A., Greve, J., \& Guimarães, G.V. (2011) Heart rate response to exercise and cardiorespiratory fitness of young women at high familial risk for hypertension: effects of interval vs continuous training. European Journal of Cardiovascular Prevention \& Rehabilitation, 18(6), pp.824-830.

2. Costin, A., Costin, N., Cohen, P., Eisenach, C., \& Marchlinski, F. (2013) Effect of exercise on heartrate response to mental stress in teenagers. European Journal of Preventive Cardiology, 20(4), pp.593-596.

3. Fjørtoft, I., Löfman, O., \& Halvorsen Thorén, K. (2010). Schoolyard physical activity in 14-year-old adolescents assessed by mobile GPS and heart rate monitoring analysed by GIS. Scandinavian Journal of Public Health, 38, (5), pp.28-37.

4. Galloway, J. (2007). Děti v kondici. Praha: Grada.

5. Jansa, P., \& Kocourek, J. (2001). Pohybové aktivity u dospělé populace v České republice. In: Optimální působeni tělesné zátěže. Hradec Králové: Gaudeamus.

6. PHIT America. Benefits of P.E. in School. (2014). PHIT America Foundation. Retrieved from http://www.phitamerica.org/Benefits_of_P_E_in_School.htm.

7. Rámcový vzdělávací program pro základní vzdělávání. (2013). Praha: MŠMT. (trans. Framework Educational Programme for Elementary Schools).

8. Snethen, J. A., \& Broome, M. E. (2007). Weight, Exercise, and Health: Children's Perceptions. Clinical Nursing Research, 16(2), pp.138-152.

9. Soumar, L. (1997). Kondice a zdraví. Praha: Polar Electro.

10. Suchomel, A. (2002). Tělesně zdatné děti - riziková skupina z hlediska prevence. In: Sborník Primárni prevence 2. Liberec: Technická universita.

11. Zhang, T., Chen, A., Chen, S., Hong, D., Loflin, J., \& Ennis, C. (Nov 2014). Constructing cardiovascular fitness knowledge in physical education. European Physical Education Review, 20(4) pp.425-443.

12. Zone optimizer. (2015). Polar Electro. Retrieved from http://www.polar.com/en/smart_coaching/features/zoneoptimizer. 